\title{
Antimicrobial Double-Layer Wound Dressing Based on Chitosan/Polyvinyl Alcohol/Copper: In vitro and in vivo Assessment
}

This article was published in the following Dove Press journal: International Journal of Nanomedicine

\author{
Ensieh Ghasemian Lemraski \\ Hossein Jahangirian $\mathbb{D D}^{2}$ \\ Maryam Dashti \\ Elaheh Khajehali $\left(\mathbb{D}^{3}\right.$ \\ Soheila Sharafinia ${ }^{4}$ \\ Roshanak Rafiee- \\ Moghaddam (iD ${ }^{2}$ \\ Thomas J Webster (iD) ${ }^{2}$ \\ 'Department of Chemistry, Faculty of \\ Science, Ilam University, Ilam, Iran; \\ ${ }^{2}$ Department of Chemical Engineering, \\ Northeastern University, Boston, MA \\ 02II5, USA; ${ }^{3}$ Department of Food \\ Hygiene, Faculty of Veterinary Medicine, \\ Ilam University, Ilam, Iran; ${ }^{4}$ Department \\ of Chemistry Faculty of Science, Shahid \\ Chamran University of Ahvaz, Ahvaz, Iran
}

Correspondence: Ensieh Ghasemian Lemraski; Hossein Jahangirian Email e.ghasemian@ilam.ac.ir; kamran.jahangirian@gmail.com
Purpose: Today, the development of wounds and their side effects has become a problematic issue in medical science research. Hydrogel-based dressings are some of the best candidates for this purpose due to their ability to keep the wound bed clean, as well as provide proper moisture, tissue compatibility and an antimicrobial effect for wound healing. On the other hand, copper and its compounds have been used experimentally for many years in studies as an antimicrobial substance. Various studies have been performed determining the antimicrobial properties of this element, during which significant effects on infection have been shown.

Methods: Chitosan/polyvinyl alcohol/copper nanofibers were successfully prepared by incorporating $\mathrm{Cu}$ onto a polymer electrospun using an electrospinning technique. A doublelayer nanofiber composed of poly(vinyl alcohol) and chitosan incorporated with $\mathrm{Cu}$ nanoparticles as a protective layer and a second layer composed of polyvinylpyrrolidone (PVP) nanofibers which was adjacent to the damaged cells was prepared. The prepared nanofiber was characterized by TGA, FT-IR, TEM, SEM-EDS, and X-ray powder diffraction. The antimicrobial efficiency of the nanofibers was demonstrated through biological tests on some Gram-positive and Gram-negative bacteria. Finally, the prepared hydrogel formulations were prepared to evaluate their effect on the healing process of rat open wounds.

Results: In this study, data from SEM, TEM, EDS, and XRD confirmed the formation of uniform fibers with nanodiameters and the presence of $\mathrm{Cu}$ nanoparticles onto the electrospun nanofibers. The antibacterial activity of copper was observed against all of the selected bacteria, but the Grampositive bacteria were more sensitive compared to Gram-negative bacteria.

Conclusion: According to the obtained results, the hydrogel wound dressing prepared in this research can be effective in caring for open wounds in the early stages of wound healing and preventing the occurrence of prolonged open wounds.

Keywords: antimicrobial, healing, hydrogel, copper, nanofiber, chitosan

\section{Introduction}

Skin, as the soft outer tissue covering the human body, maintains water and temperature and protects the muscles, ligaments, organs and bones. However, bacterial infections established during wound healing can reduce healing speed and increase the risk of diseases.

Chronic wounds are caused by certain diseases and physical conditions. The diseases that lead to chronic wounds are vascular, venous and arterial diseases, diabetes, as well as bed sores. Significant statistics in the world highlight the on-going suffering from chronic wounds, which account for one to two percent of society. For example, chronic wounds 
in the United States generate $\$ 25$ billion to $\$ 100$ billion in economic burden, and millions of people are looking for new treatments. ${ }^{1}$ In Iran, according to statistics, six million people with diabetes and $25 \%$ of those with chronic wounds lead to one and a half to two and a half million people with chronic wounds, especially lower limb ulcers. These people are in danger, and $28 \%$ of people with diabetic foot ulcers die after two years. ${ }^{2,3}$

So, it is necessary to synthesize an antimicrobial wound dressing in order to avoid the growth of photogenic microorganisms.

There are many methods to fabricate such wound dressings such as drawing, self-assembly, directed temperature synthesis and electrospinning. Between the reported methods, electrospinning is a simple, rapid, efficient, cost-effective and reproducible technique to prepare fibers with a diameter on the micron or even nanometer scale with high surface area. ${ }^{3-5}$ In nanomaterials, the ratio of surface area to volume increases and, as a result, the ratio of surface atoms to total atoms increases. Since surface atoms affect the properties of materials, they show quantum special behavior such as in optical, electrical, magnetic, and chemical properties. In addition, due to the high surface-to-volume ratio of electrified fibers, they easily stabilize enzymes and other biological catalysts. Research has indicated that electrospun nanofibers are good candidates for tissue scaffolding, ${ }^{6}$ drug release, ${ }^{7}$ simplifying gas permeation and overall for wound dressings. ${ }^{3}$ Moreover, wound dressings play an important role in wound healing, extraction of excess fluid around the wound, disinfection of external microorganisms, and accelerating the healing process. ${ }^{8,9}$ Recently, multilayer nanofibrous mats have been more commonly used than commercial models due to their distinctive features compared to pristine nanofibrous mats.

Further, natural polymers, due to their biodegradability and biocompatibility, non-antigenic and non-toxic wound healing properties, are some of the materials being used for wound dressings. ${ }^{9,10}$

Commonly studied polymers for fabricating wound dressing mats are chitosan, ${ }^{11}$ polyethylene oxide (PEO), ${ }^{12}$ poly (vinyl alcohol) (PVA), ${ }^{13}$ and PVP (polyvinylpyrrolidone). ${ }^{14}$ In this study, we used chitosan, PVP (polyvinylpyrrolidone), and PVA polymers. Chitosan is a natural polymer that has excellent biological properties including wound healing, antibacterial activity and a low cost of isolation and processing. ${ }^{10}$ Therefore, to enhance the antibacterial activity of dressing mats, chitosan has been considered to be one of the best bio macromolecules for tissue-engineered scaffolds and wound dressings. ${ }^{11}$ PVA is another polymer used in electrospinning due to its excellent fiber-forming ability, chemical resistance properties against strong solvents including aromatics, aliphatics, and chlorinated solvents, and biocompatibility in cardiac scaffold production, skin, bone, and cartilage tissues. ${ }^{13}$ In the present work, we have produced a double-layer electrospun nanofiber based on PVA, chitosan, and PVP. The first layer (PVA/CS/CuNPs) with antimicrobial effects was in contact with the environment and the second layer, which was in contact with the injured site, was a composite of electrospun PVP nanofibers. For many years, silver and copper have been mentioned as antimicrobial metals. As we know, copper and copper compounds have biocidal ability, and as a result, many medical instruments have been shown effective in the fight against hospital-acquired infections. Researchers have shown that copper is able to kill Gram-positive and Gram-negative bacteria across all temperatures and all levels of humidity. This behavior is important since antimicrobial activity must be possible at a typical patient room's ambient temperature and relative humidity. Also, copper exists in two ionic states in compounds, making it a more active element regardless of the presence of moisture for an oxidizer. ${ }^{15-21}$

To study and characterize the prepared nanofibers, we used SEM, TEM, XRD, FT-IR, EDS, and TGA analysis. The wound healing and antimicrobial efficiency of the nanofibers were further demonstrated through biological tests and healing of open excision type wounds in albino rats, showing much promise.

\section{Materials and Methods Chemicals}

The following materials were used in this study including: PVA (89000-98000 Da; +99\%; hydrolyzed), chitosan (190000-310000 Da) (CS), PVP (1300000 Da), and copper nitrate $\left(\mathrm{Cu}\left(\mathrm{NO}_{3}\right)_{2}\right)$, all purchased from Sigma-Aldrich Co. (St. Louis, MO, USA). Tetracycline as oinment and tablet was purchased from Tolide Darouhai Dami Iran(TDDI) company.

\section{Instruments and Characterization}

An electrospinning device was used to produce nanofibers and included the following specifications: a high voltage power source (nano Azma Company, Tehran, Iran), a syringe pump (LSP02-1B, Longer Precision Pump Co., Ltd., Shafa Syrinqe Manufacturing Company, Tehran, Iran), a voltage-stabilized source (POWER-01) and an electrical collector. To specify the diameter and morphology of the PVA/CS/CuNPs/PVP nanofibers, scanning 
electron microscopy (SEM, Tescan model, Vega Company, Kohoutovice, Czech Republic) was used. Also, transmission electron microscopy (TEM) (JEM-2100, JEOL, Tokyo, Japan) images were used to investigate the morphology of the nanoparticles used in this work. In this regard, the electrospinning process was done on a copper grid. Then, the grid covered with nanofibers was analyzed using TEM . The crystallinity of the electrospun PVA/CS/ CuNPs nanofiber mats was investigated via an X-ray diffractometer (XRD, Philips PW 1800 X'PERT). A Fourier transform infrared (FT-IR, Vertex model, Bruker Corporation Inc., Billerica, MA, USA) spectrometer was used to identify the functional groups on the surface of the electrospun nanofibers. The thermal decomposition experiments of the samples were performed using a STA/TGA (Simultaneous Thermal Analysis) NETZSC model, NETZSC Company (Germany).

\section{Methods}

\section{Preparation of the PVA/CS/CuNPs First Layer}

Initially, the electrospinning solution was prepared by dissolving $1.5 \mathrm{~g}$ PVA in $8.5 \mathrm{~mL}$ of distilled water and magnetically stirring at $80{ }^{\circ} \mathrm{C}$ until a homogeneous solution was achieved. Then, separately, $0.1 \mathrm{~g}$ CS and 0.004 $\mathrm{g} \mathrm{Cu}\left(\mathrm{NO}_{3}\right)_{2}$ were dissolved in $20 \mathrm{~mL} 2 \%$ molar acetic acid solution and magnetically stirred. In the next step, the solution containing chitosan and $\mathrm{Cu}$ particles and the PVA solution was mixed and magnetically stirred until it completely blended. Immediately, the solutions were loaded into a glass syringe and electrospinning was performed under $18 \mathrm{kV}$ and the tip-to-collector distance was fixed at $10 \mathrm{~cm}$.

\section{Preparation of the PVP Second Layer}

The second layer was prepared as follows: initially, 1.2 gof PVP was dissolved in $300 \mathrm{~mL}$ of distilled water and magnetically stirred at $80{ }^{\circ} \mathrm{C}$ until achieving a jelly solution, and then the electrospun solutions were prepared on the first layer by an electrospinning technique. All the prepared nanofibers were sterilized by UV light before application in cell and animal experiments.

\section{Preparation of Microbial Inoculums and Culture Media}

In the present study, four microbial species were used: Gram-positive bacteria, Staphylococcus aureus (ATCC 25923) and Bacillus cereus (ATC 11788); and Gramnegative bacteria, Escherichia coli (ATCC 35218) and Pseudomonas aeruginosa (ATCC 49189). All of the cultures were transferred to tryptic Soy Broth (TSB) media and incubated at $37^{\circ} \mathrm{C}$ for $24 \mathrm{~h}$.

\section{In vitro Antibacterial Sensitivity Test}

The antibacterial activity of the copper nanoparticles against the selected Gram-negative and Gram-positive bacteria was determined using the Disk Diffusion Susceptibility Test method. ${ }^{22,23}$ The bacteria strains were regulated to a $0.5 \mathrm{McFarland}$ value of standard turbidity $\left(1.5 \times 10^{-8} \mathrm{CFU} / \mathrm{mL}\right)$ which were later spread on MuellerHinton agar (MHA) (Merck KGaA, Darmstadt, Germany). The susceptibility assay of bacteria to standard antibiotics, tetracycline, was performed using microdilution method in concentration about $0.08 \mu \mathrm{g} \mathrm{ml}^{-1}$. A sterile blank antimicrobial susceptibility disk was impregnated with $20 \mu \mathrm{L}$ of a freshly prepared sample and was placed on agar plates incubated with tested pathogenic strains at $37{ }^{\circ} \mathrm{C}$ for 24 h. The inhibition zone was observed and measured after 24 $\mathrm{h}$ of incubation.

\section{In vivo Wound Healing Study}

Twenty-five healthy adult male Wistar albino rats (200$250 \mathrm{~g}$ ) were used in the present study. The Ilam University Animal Care and Use Committee approved all experimental protocols, and the experiments were conducted in compliance with their guidelines. Randomly selected rats were divided into 5 (1-5) groups of 6 rats each: gauze (negative control), tetracycline (positive control), PVA, PVA/CS, and PVA/CS/Cu.

The dorsal skin of the rats was shaved and cleaned with $70 \%$ ethanol. A $1.5 \mathrm{~cm} \times 1.5 \mathrm{~cm}\left(225 \mathrm{~mm}^{2}\right)$ full-thickness open excision-type wound was created on the backside of each rat under light ether anesthesia. ${ }^{24}$ The animals were then housed in properly disinfected cages at a room temperature of $25 \pm 2^{\circ} \mathrm{C}$. Tetracycline ointment was also applied to the wounds in positive controle group.On days $0,3,7$, 11 and 15, margins of the wounds were photographed and the rate of wound closure was determined by the following equation:

$\%$ wound contraction $=(0-$ day wound area - unhealed wound $) \times 100 /(0-$ day wound area $)(1)$

\section{In vitro $\mathrm{Cu}$ Release Test}

The antimicrobial activity was also determined by $\mathrm{Cu}$ release tests from the nanofibers. In order to determine $\mathrm{Cu}$ ion release, $1 \mathrm{~g}$ of the nanofibers was incubated in $50 \mathrm{~mL}$ of PBS for 72 h. then $1 \mathrm{~mL}$ of the sample was collected at different times 

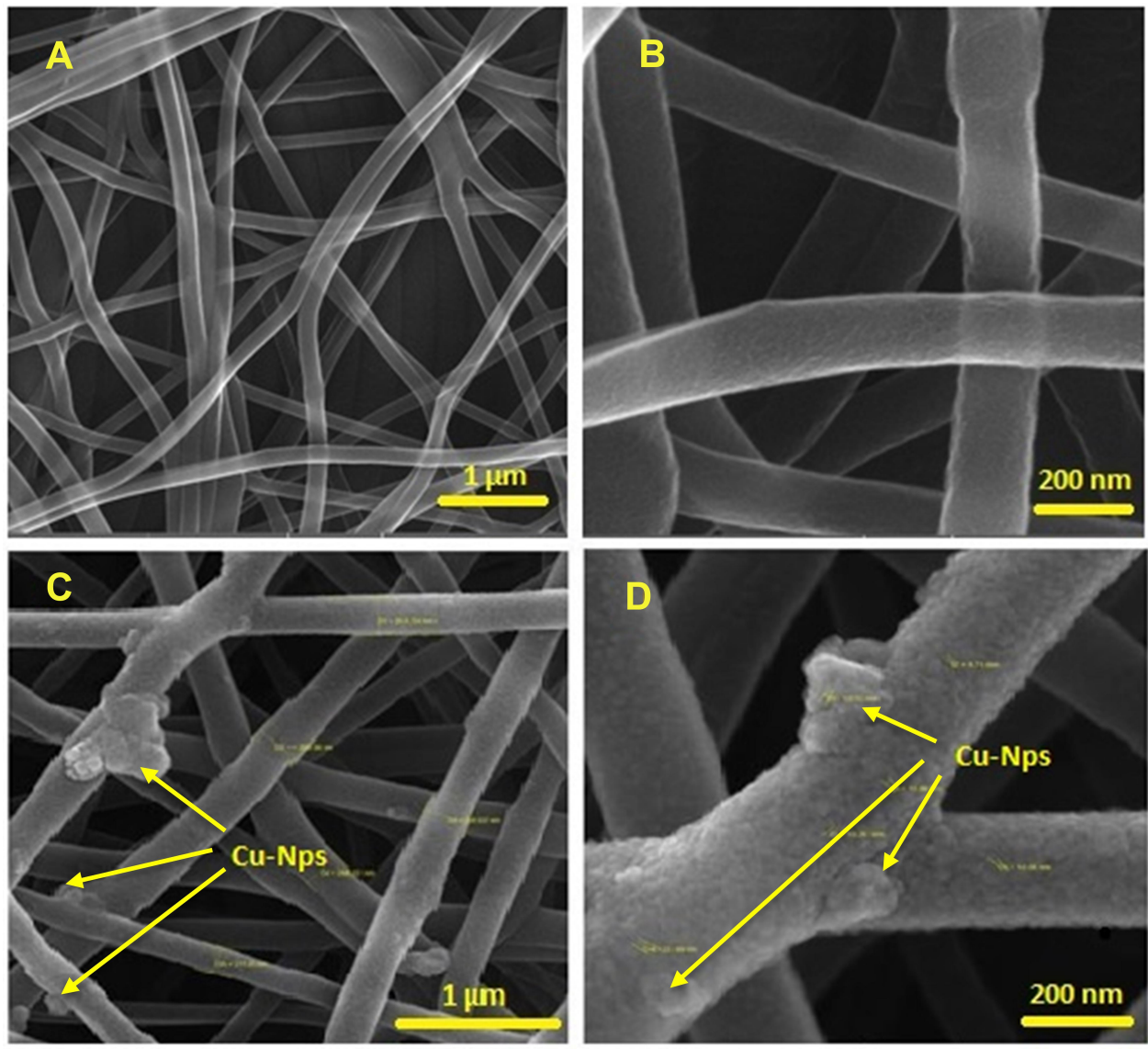

Figure I SEM images of the PVA/CS (A, B) and PVA/CS/CuNPs nanofibers (C, D).

(30 min, 1, 2, 4, 8, 24, 48, and $72 \mathrm{~h}$ ), and replaced with $1 \mathrm{~mL}$ of a fresh PBS buffer solution. ${ }^{25}$

\section{Results}

\section{Characterization}

Scanning Electron Microscopy (SEM) of the PVA/CS/ Cu Nanofibers

Figure 1 shows the surface morphology and size of the nanofibers obtained from scanning electron microscopy (SEM) analysis. As Figure 1 shows, the PVA/CS/Cu nanofibers had a diameter between 200 to $300 \mathrm{~nm}$. In addition, according to Figure 1, the SEM image confirmed the suitable concentration and condition of the solution for preparing clear and uniform electrospun fibers without any beads or microporous nanofibrous networks. On the other hand, $\mathrm{Cu}$ nanoparticles were seen on the surface of the PVA/Cs nanofibers. SEM images showed an adequate and desirable dispersion of $\mathrm{Cu}$ nanoparticles in the polymer matrix with a size between $50-100 \mathrm{~nm}$. The aggregation of the nanoparticles could be seen in parts of the nanofibers.
Energy Dispersive X-Ray Spectroscopy (EDX) of the PVA/CS/Cu Nanofibers

Figure 2 displays the energy dispersive $\mathrm{X}$-ray (EDX) results of the PVA/CS/CuNPs nanofibers. The binding peaks at $0.285,0.39$, and $0.530 \mathrm{keV}$ in Figure 2 represents the presence of $\mathrm{C}, \mathrm{N}$, and $\mathrm{O}$ in the nanofibers due to the $\mathrm{PVA} / \mathrm{CS}$ composition of the electrospun fibers. Also, EDX spectra of the nanofibers displayed some peaks which revealed the presence of $\mathrm{Cu}$ NPs in the electrospun nanofibers. Compared to the carbon and nitrogen EDS peaks, peaks around $0.9,8$, and $9 \mathrm{keV}$ with very weak intensities, are due to the low amount of copper in the nanofiber structure. Similar results have been reported in the literature. ${ }^{25,26}$

\section{Transmission Electron Microscopy (TEM) of the PVA/ CS/Cu Nanofibers}

The TEM images of the prepared electrospun nanofibers are shown in Figure 3. The TEM images of the prepared nanofibers in Figure 3 show that the diameter of the nanofibers were around $100 \mathrm{~nm}$. Besides, the CuNPs were successfully loaded onto the PVA/CS nanofibers. 


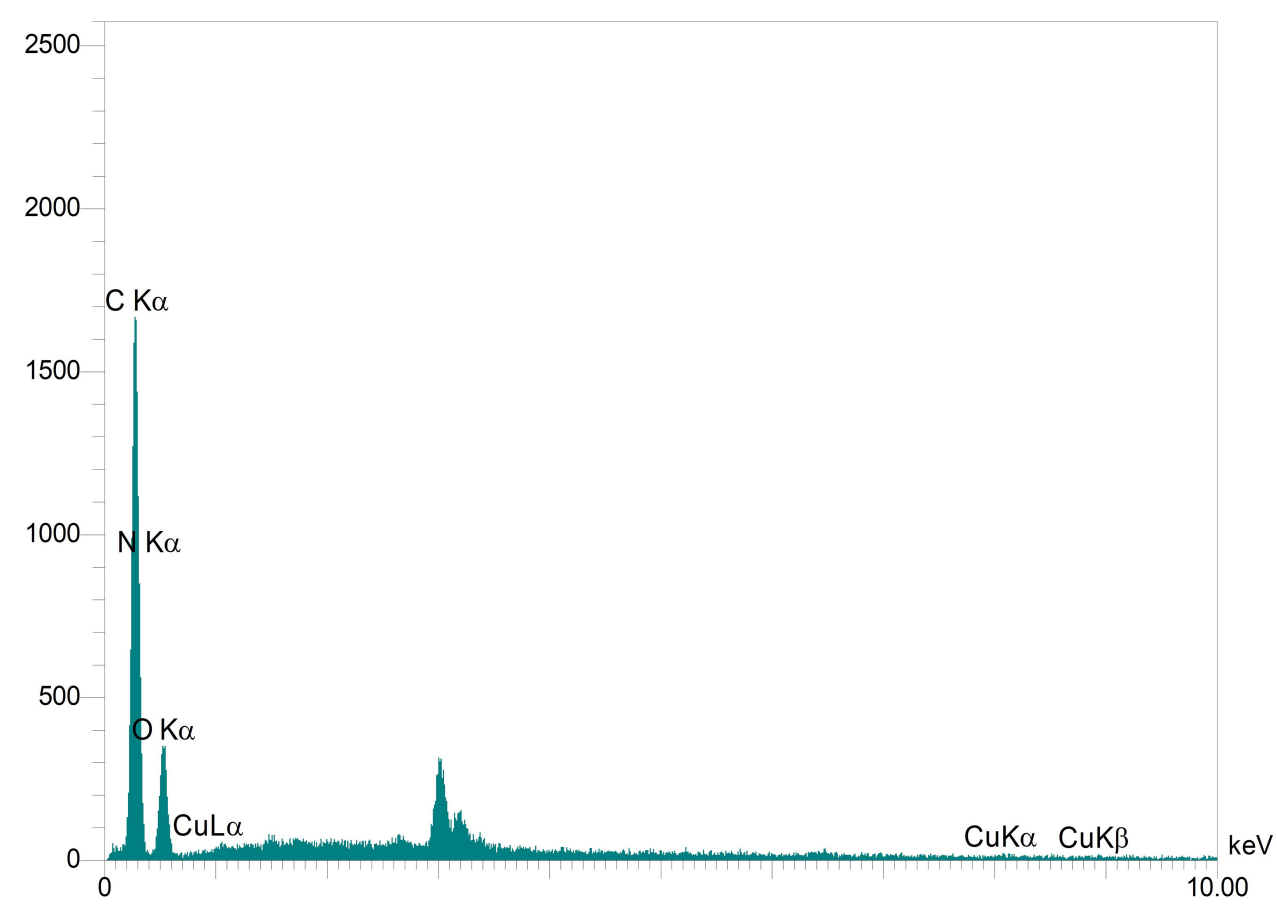

Figure 2 EDX spectra of the PVA/CS/CuNPs nanofibers.

\section{X-Ray Diffraction (XRD)}

Figure 4 shows the crystal pattern of the PVA/CS/CuNPs nanofibers obtained from X-ray diffraction (XRD) analysis. The relatively broad peak at $2 \theta=20^{\circ}$ exhibited the amorphous structure of the polymer in the nanofiber. In addition, the location of the polymer peak was not affected noticeably by the incorporation of $\mathrm{Cu}$ nanoparticles. The

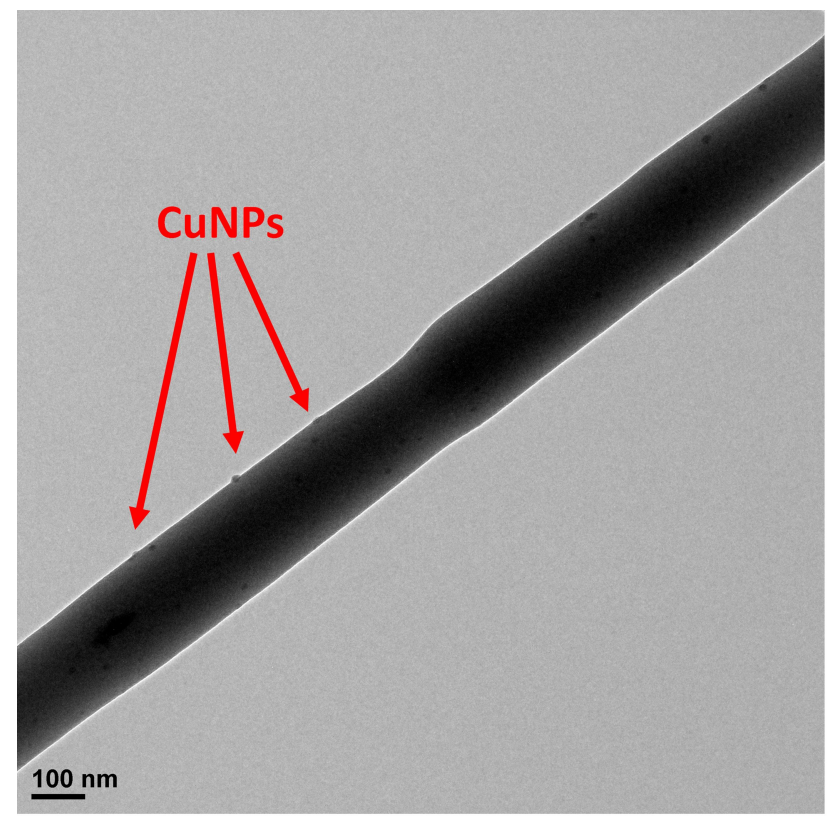

presence of a broad peak at about $2 \theta=32^{\circ}$ and $50^{\circ}$ was attributed to the (111) and (200) planes of the fcc structure of the copper nanoparticle, respectively. ${ }^{26,27}$ The small and wide peaks indicated the formation of copper nanoparticles on the nanofibers. Generally, based on the obtained results, it can be said that copper nanoparticles were successfully fabricated on the nanofibers.

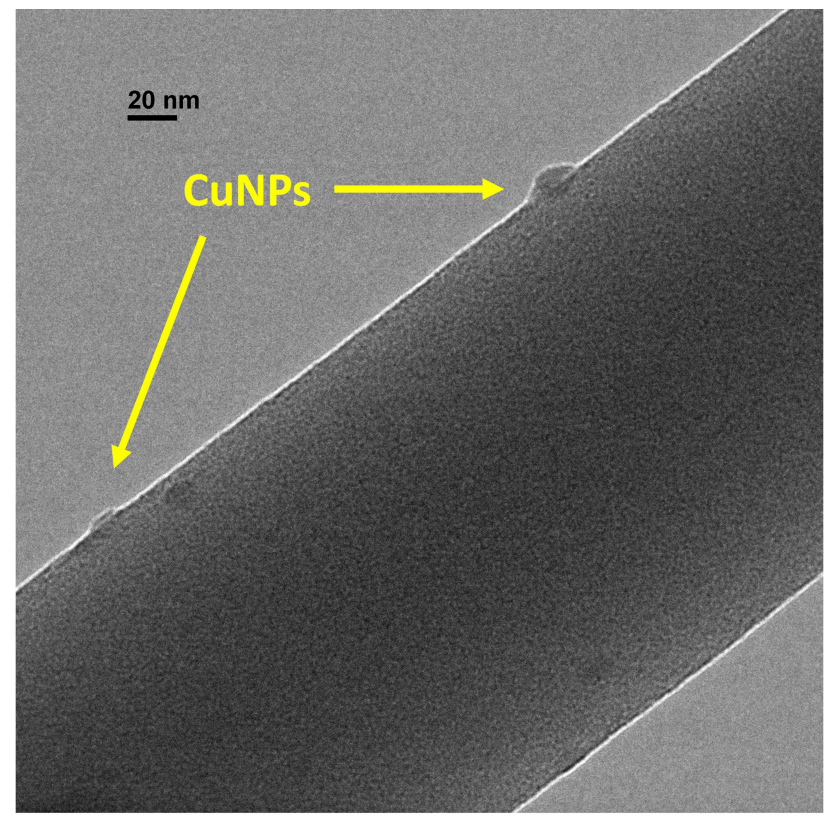

Figure 3 TEM images of the PVA/CS/CuNPs nanofibers. 


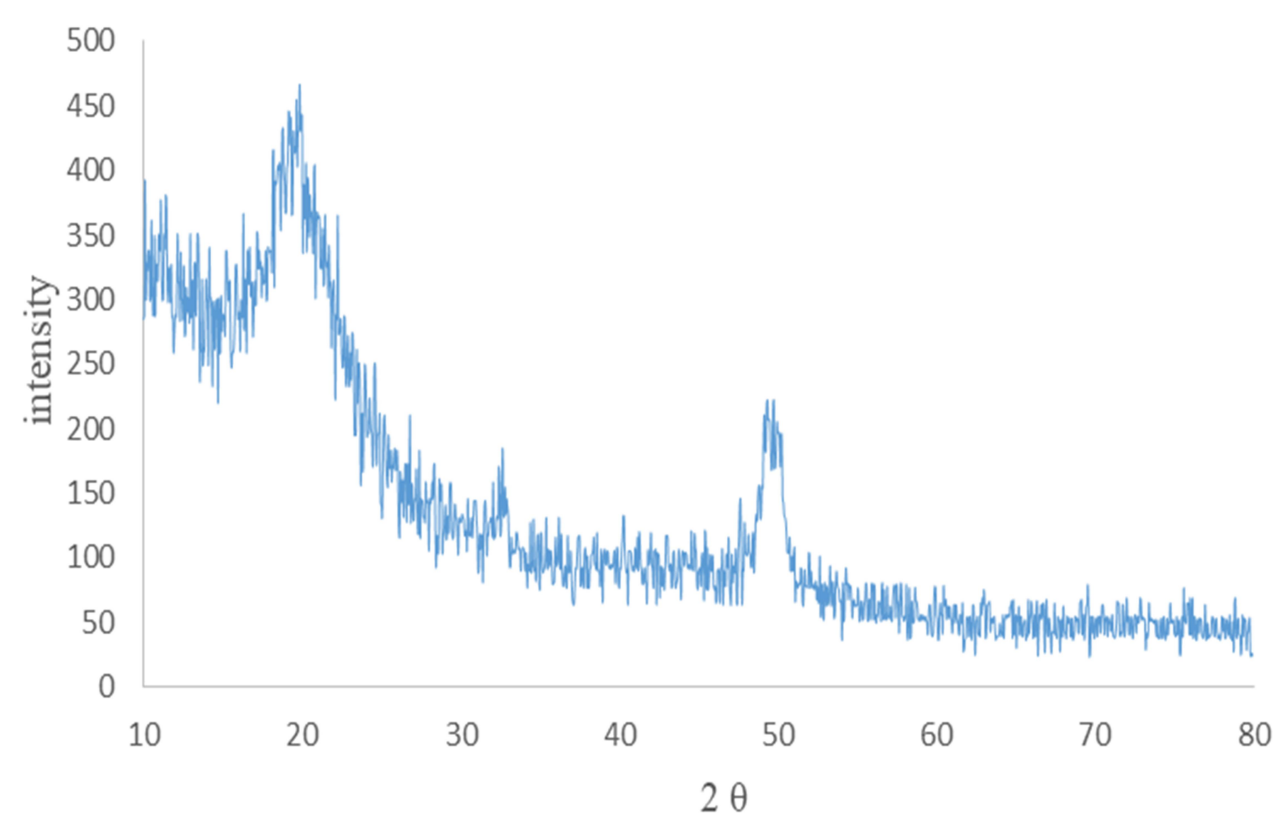

Figure 4 XRD pattern of the PVA/CS/Cu nanofibers.

\section{FT-IR Spectroscopy}

The presence of the functional groups on the surface of pure PVA, PVA/CS, and PVA/CS/CuNPs nanofibers using FTIR analysis is shown in Figure 5. As seen from the diagram, all three spectra were similar and there was no significant difference between them. In Figure 5, the peak at $1105 \mathrm{~cm}^{-1}$ and $1638 \mathrm{~cm}^{-1}$ indicated the $\mathrm{C}=\mathrm{O}$ group of ether and the $\mathrm{OH}$ stretching group, respectively. Furthermore, the weak bands shown at $2854 \mathrm{~cm}^{-1}$ and $2924 \mathrm{~cm}^{-1}$ were attributed to the symmetric and asymmetric bending vibrations of the methylene group. The stretching vibration of the $\mathrm{OH}$ groups and hydrogen bonds were indicated in the $3464 \mathrm{~cm}^{-1}$ region. ${ }^{21}$ The spectrum of the cross-linked PVA/CS is shown in Figure 5. The peaks in the regions $3465 \mathrm{~cm}^{-1}$ and $2854 \mathrm{~cm}^{-1}$ indicated the $\mathrm{N}-\mathrm{H}$ and $\mathrm{C}-\mathrm{H}$ stretching vibration, respectively. The peak at $1638 \mathrm{~cm}^{-1}$ indicated the carboxymethyl group reaction with the amino groups of chitosan forming a secondary amide. ${ }^{28}$ Also, the peak in region $10,384 \mathrm{~cm}^{-1}$ indicated the presence of $\mathrm{CH}_{3}$ symmetrical groups. Peaks in the regions $1044 \mathrm{~cm}^{-1}$ and $618 \mathrm{~cm}^{-1}$ were due to the chitosan saccharide structure..$^{29,30}$ The stretching vibration of the $\mathrm{N}-\mathrm{H}\left(3465 \mathrm{~cm}^{-1}\right) \mathrm{PVA} / \mathrm{CS} / \mathrm{CuNPs}$ nanofiber bands is shown in Figure 5.

\section{Thermal Gravity Analysis (TGA)}

The results of TGA analyses for PVA, PVA/CS, and PVA/ $\mathrm{CS} / \mathrm{CuNPs}$ are given in Figure 6. As can be seen from Figure 6, PVA is decomposed into two stages. The first stage of decomposition ( $w t \% 78.70$ ) occurred at $220{ }^{\circ} \mathrm{C}$ due to hydroxyl side group elimination. ${ }^{5}$ The second decomposition $(\mathrm{wt} \% 10.88)$ at $400^{\circ} \mathrm{C}$, is related to the breakdown of the $\mathrm{C}-\mathrm{C}$ bond at side chains and the conversion of the polymer into carbon and hydrocarbons. Generally, water, aldehydes, and methyl ketones are the main derivatives formed from the unsaturation in the polymer chain due to the thermal decomposition of PVA. ${ }^{5,31}$ The TGA curves for PVA/CS nanofibers revealed decomposition of the sample in two stages. The wt $\%$ of 79.53 and $w t \%$ of 8.35 from the decomposition occurred at $220^{\circ} \mathrm{C}$ and $390{ }^{\circ} \mathrm{C}$, which is related to moisture removal and decomposition of the polymers PVA and CS, respectively. The weight percent loss decreased with increasing chitosan in the mixture. In comparison, PVA/CS/ CuNPs showed a little more stability than pure PVA and $\mathrm{PVA} / \mathrm{CS}^{31}$

\section{Copper Ion Release Test}

It is evidenced that slow $\mathrm{Cu}^{2+}$ release is an advantage due to the antimicrobial activity of the nanofibers. Figure 7 shows the release of copper as a function of time. In the initial time of release, the quantity increased very quickly and then remained almost constant for up to $12 \mathrm{~h}$. This behavior might be due to the higher concentration of $\mathrm{Cu}$ ions in the nanofiber at initial time periods. The results obtained from the present work is in good agreement with the data reported in the literature. ${ }^{25}$ This result is very important in the preparation of medical devices, wound dressings, personal care products, veterinary, military, and protective clothing. Beside as an important role in the 


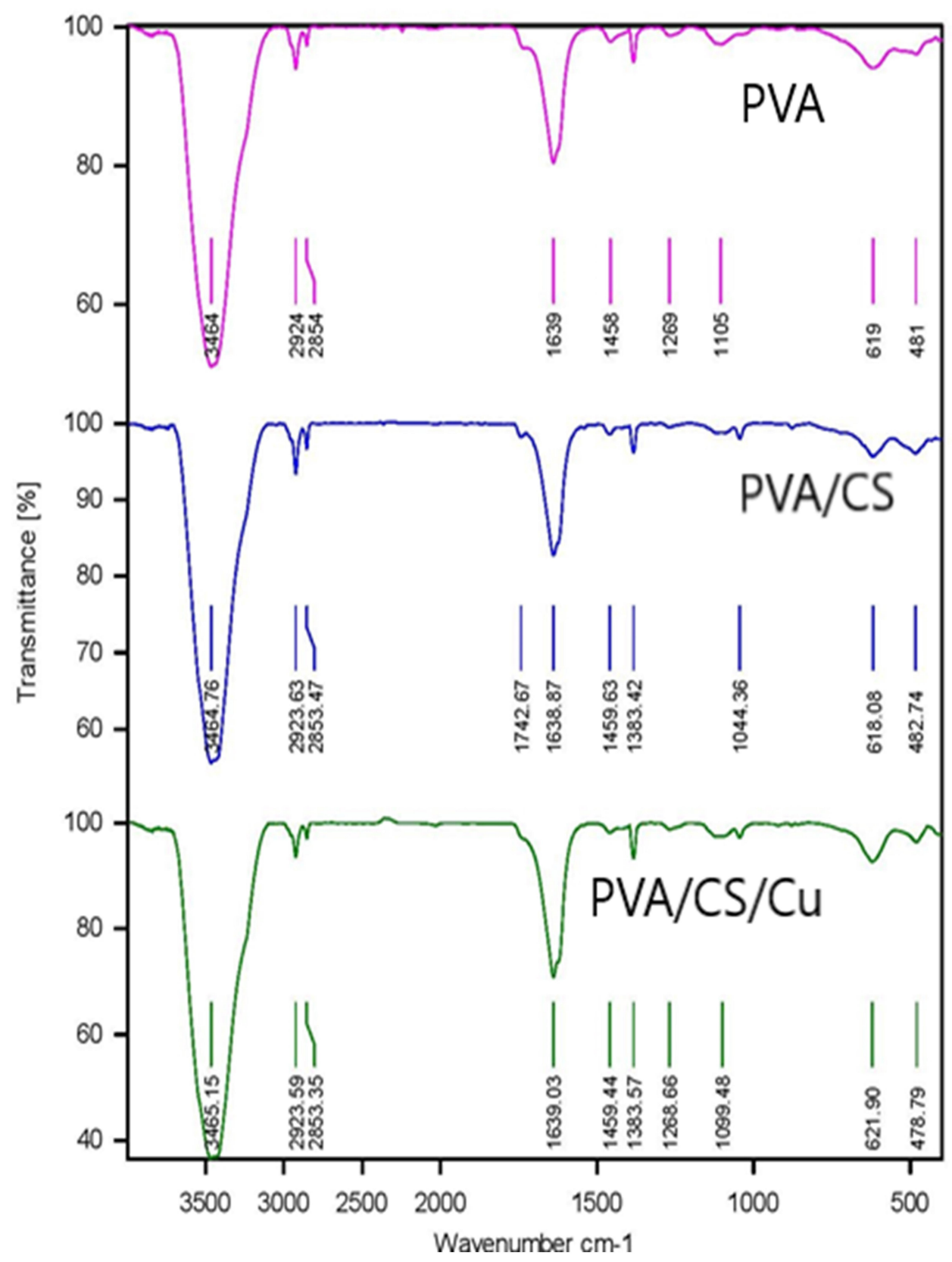

Figure 5 FT-IR spectra of the PVA, PVA/CS, and PVA/CS/CuNPs nanofibers.

synthesis and stabilization of skin proteins, a slow release of $\mathrm{Cu}$ provides high biocidal activity for medical processes. ${ }^{25}$

\section{Antimicrobial Susceptibility Test}

The disc diffusion procedure was conducted to assess the antimicrobial activity of copper nanoparticles against four species of bacteria, E. coli and P. aeruginosa (Gramnegative), $S$. aureus and Bacillus cereus (Gram-positive). The inhibition zone diameter produced by each sample was measured and an antibiotic disc (tetracycline 30 $\mathrm{gg}$ ) was used as a control group (Figure 8). The results showed that the PVA and PVA/CS sample did not exhibit any antibacterial activity against any of the tested microorganisms. PVA/CS/CuNPs showed inhibition against all tested microorganisms. The strongest activity was against Bacillus cereus $(29.6 \pm 0.42 \mathrm{~mm})$, followed by $S$. aureus (15.6 \pm 1.1$),$ E. coli $(13.3 \pm 0.8)$ and then by P. aeruginosa $(10 \pm 1 \mathrm{~mm})$ (Table 1).

As shown in Figure 8, the antibacterial activity of copper was observed against all of the selected bacteria but the Gram-positive bacteria were more sensitive 


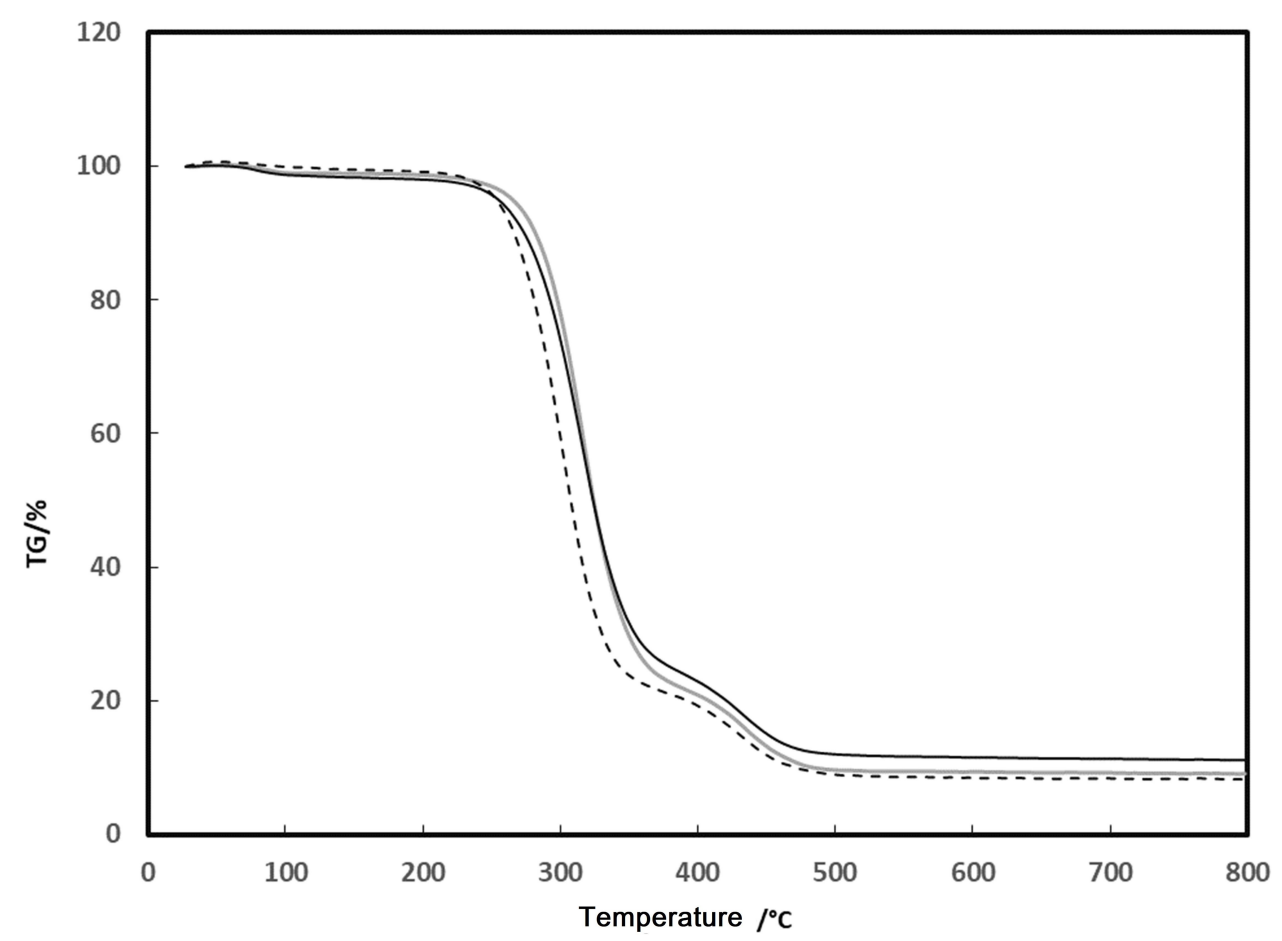

Figure 6 TGA curves of the PVA (gray solid line), PVA/CS (dashed line), and PVA/CS/Cu nanofiber (black solid line).

compared to Gram-negative bacteria. In each sample, there was about $0.004 \mathrm{~g} \mathrm{Cu}\left(\mathrm{NO}_{3}\right)_{2}$. The difference in susceptibility between the two classes of bacteria could be because of their basic difference in cell wall structure. ${ }^{32}$ Copper induces cytoplasmic leakage by the interaction between the surface and bacterial outer membrane causing the membrane to rupture. ${ }^{33}$ Copper also can cause reactive oxygen species (ROS) production to increase to a level that is toxic to the cell, and is able to disrupt the cell membrane and cell death. ${ }^{34}$

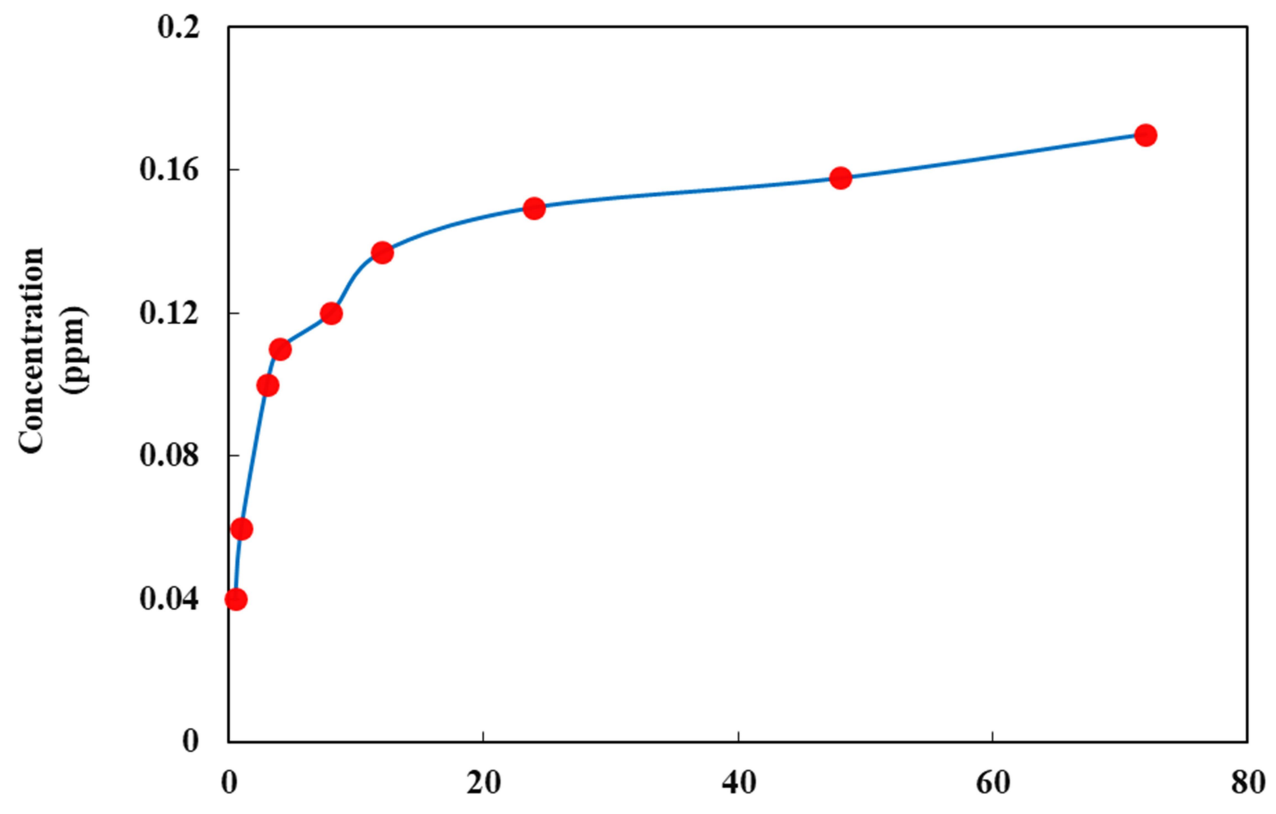

Time (hours)

Figure $7 \mathrm{Cu}$ release test as a function of time. 

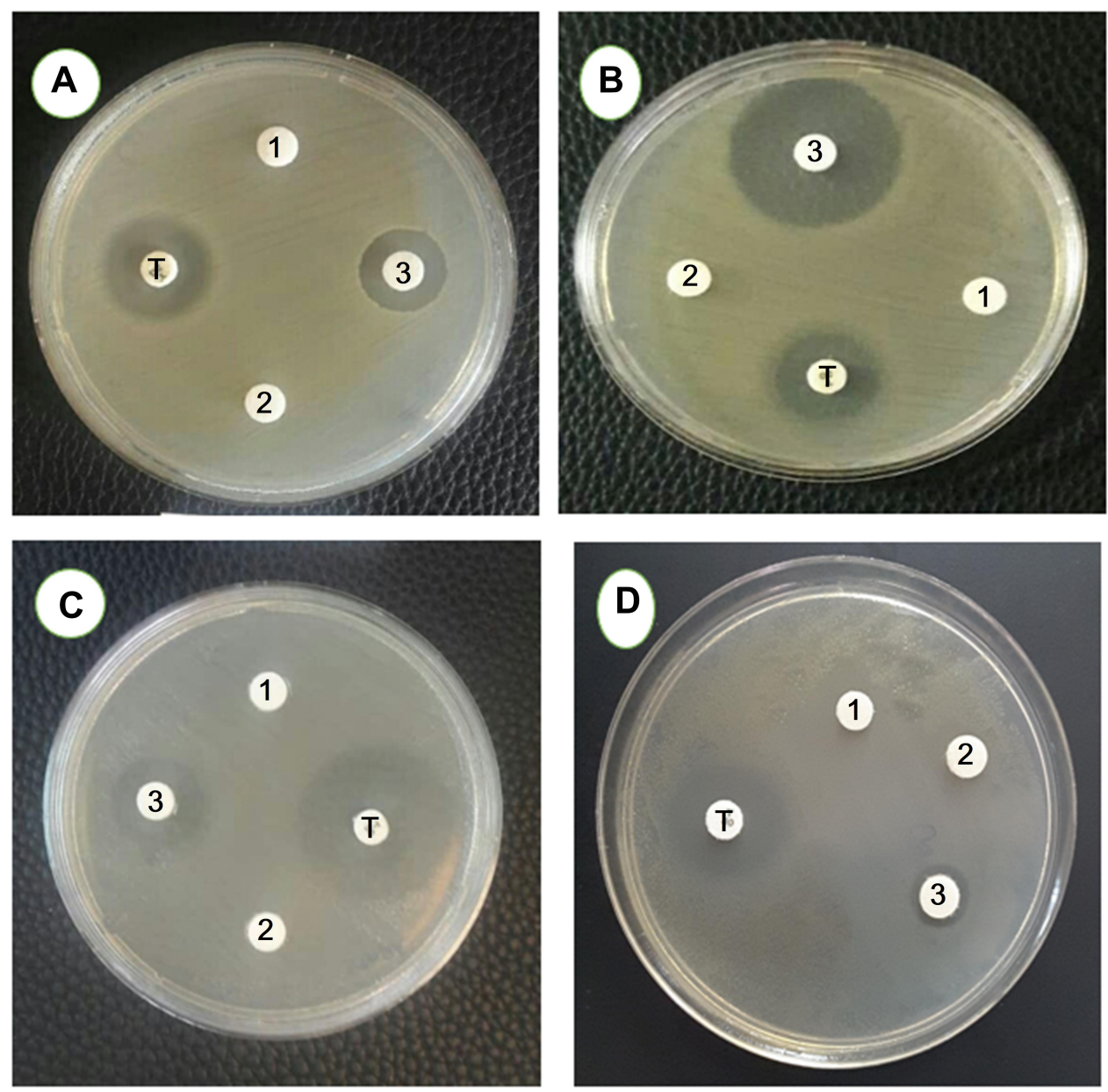

Figure 8 Antimicrobial susceptibility disk diffusion test. (A) Escherichia coli, (B) Bacillus cereus, (C) Staphylococcus aureus, and (D) Pseudomonas aeruginosa with I) PVA, 2) PVA/CS, 3) PVA/CS/CuNPs and T) Tetracycline (Control).

\section{In vivo Wound Healing Properties}

Representative images of the wound area for all of the five groups of rats on days $0,3,7,11$ and 15 are given in Figure 9. On the day of surgery, no visible differences in wound appearance was observed for all groups but the percent increase in the wound contraction was found to increase for all the groups with time. On day 16 , the PVA/CS/CuNP treated group showed complete healing. Figure 10 showed the percentage of wound closure of the positive control, negative control, PVA, PVA/CS, and PVA/CS/CuNPs. The wound closure rate of the negative control group was $18.46 \%, 59.89 \%, 88.07 \%$, and $62.42 \%$ and the wound closure rate of the positive control group was $25.33 \%, 72.85 \%$, $95.32 \%$, and $97.90 \%$ for 3, 7, 11 and 15 days, respectively.

Although the wound area was also significantly decreased in the chitosan treated group, the effect was more pronounced in the PVA/CS/CuNPs treated group, suggesting the increased effect of this group in improving cutaneous wound healing with chitosan. In the present study, the wound closure rate for the PVA treated group was $20.38 \%$, for PVA/ CS was $22.49 \%$ and for PVA/CS/CuNPs was $35.92 \%$ on day 3 respectively; this shows that the copper nanoparticles induced a sharp decrease in the wound surface area on the third day after application in the rat which is the same that as reported in the literature. In a recent study, copper

Table I Disc Diffusion Analysis of: Treatment I: PVA, Treatment 2: PVA/Chitosan and Treatment 3: PVA/Chitosan/CuNPs. Each Value is the Mean \pm SD of Triplicate Analysis

\begin{tabular}{|c|c|c|c|c|}
\hline \multirow{2}{*}{$\begin{array}{l}\text { Bacteria } \\
\text { Strains }\end{array}$} & \multicolumn{4}{|c|}{ Inhibition Zone (mm) } \\
\hline & PVA & $\begin{array}{l}\text { PVA/ } \\
\text { Chitosan }\end{array}$ & $\begin{array}{l}\text { PVA/ } \\
\text { Chitosan/ } \\
\text { CuNPs }\end{array}$ & Tetracycline \\
\hline Bacillus cereus & 0 & 0 & $29.6 \pm 0.42$ & $20.2 \pm 0.6$ \\
\hline P. aeruginosa & 0 & 0 & $10 \pm 1$ & $18.9 \pm 0.32$ \\
\hline Escherichia coli & 0 & 0 & $13.3 \pm 0.8$ & $19.8 \pm 0.5$ \\
\hline $\begin{array}{l}\text { Staphylococcus } \\
\text { aureus }\end{array}$ & 0 & 0 & $|5.6 \pm 1|$. & $25.5 \pm 1$ \\
\hline
\end{tabular}




\section{Negative control}
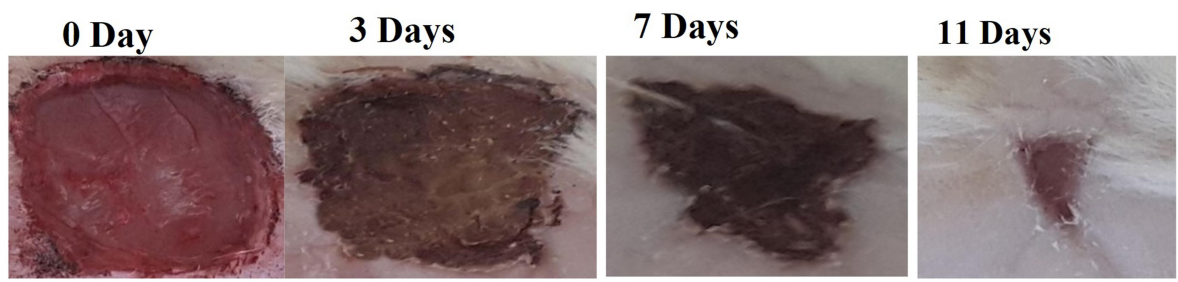

15 Days

Positive control

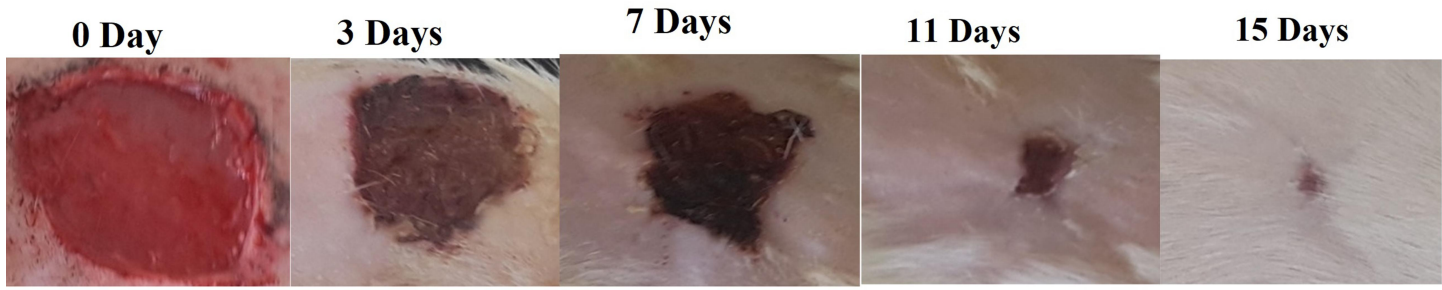

PVA

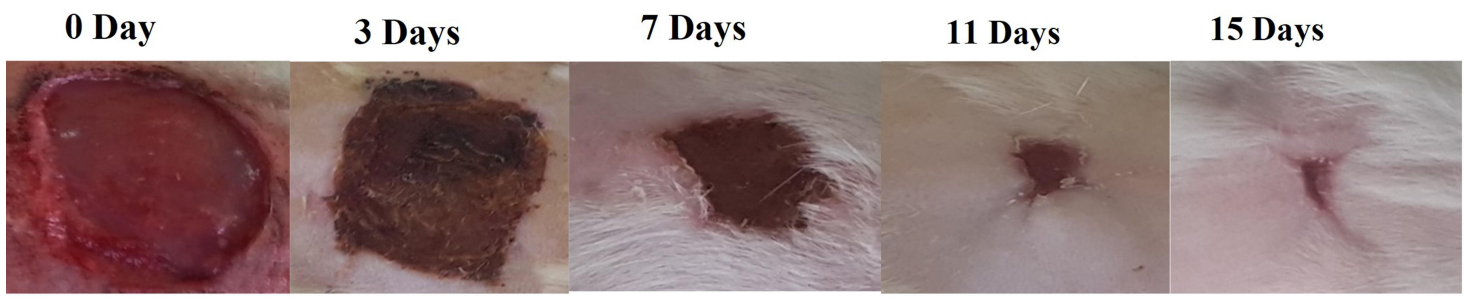

PVA/ Chitosan

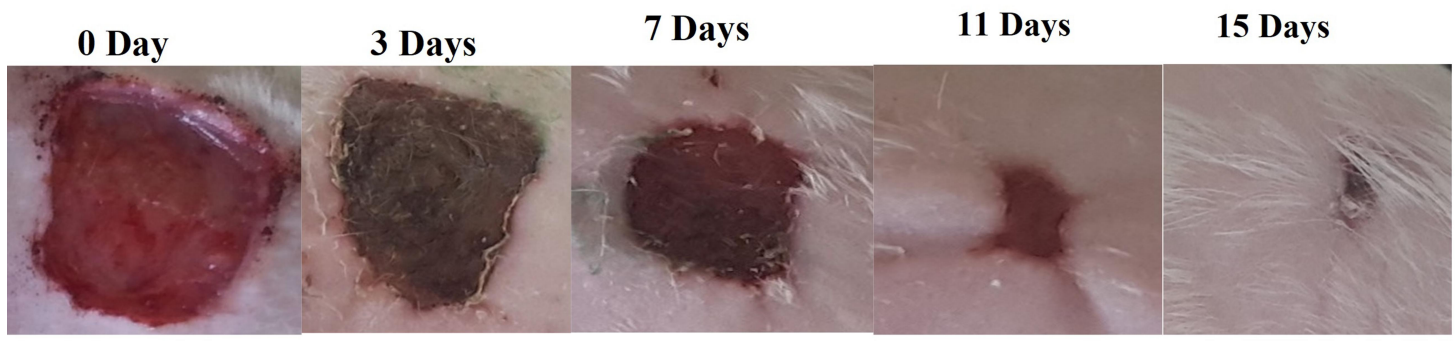

PVA / chitosan / CuNPs

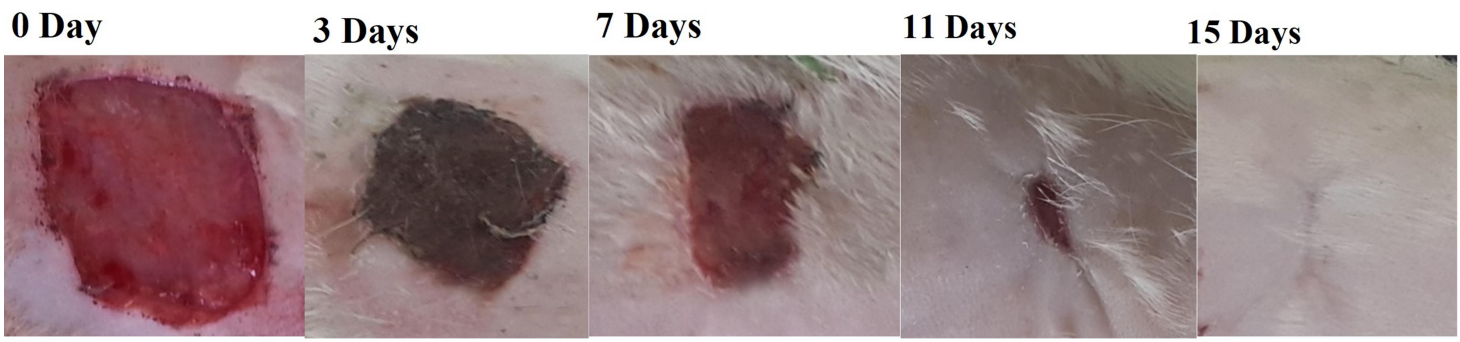

Figure 9 In vivo result of wounds in adult male albino rats. Images of the wound area of all five groups of rats on days $0,3,7, I I$, and I5 and for the positive control, negative control, PVA, PVA/CS, and PVA/CS/CuNPs. 


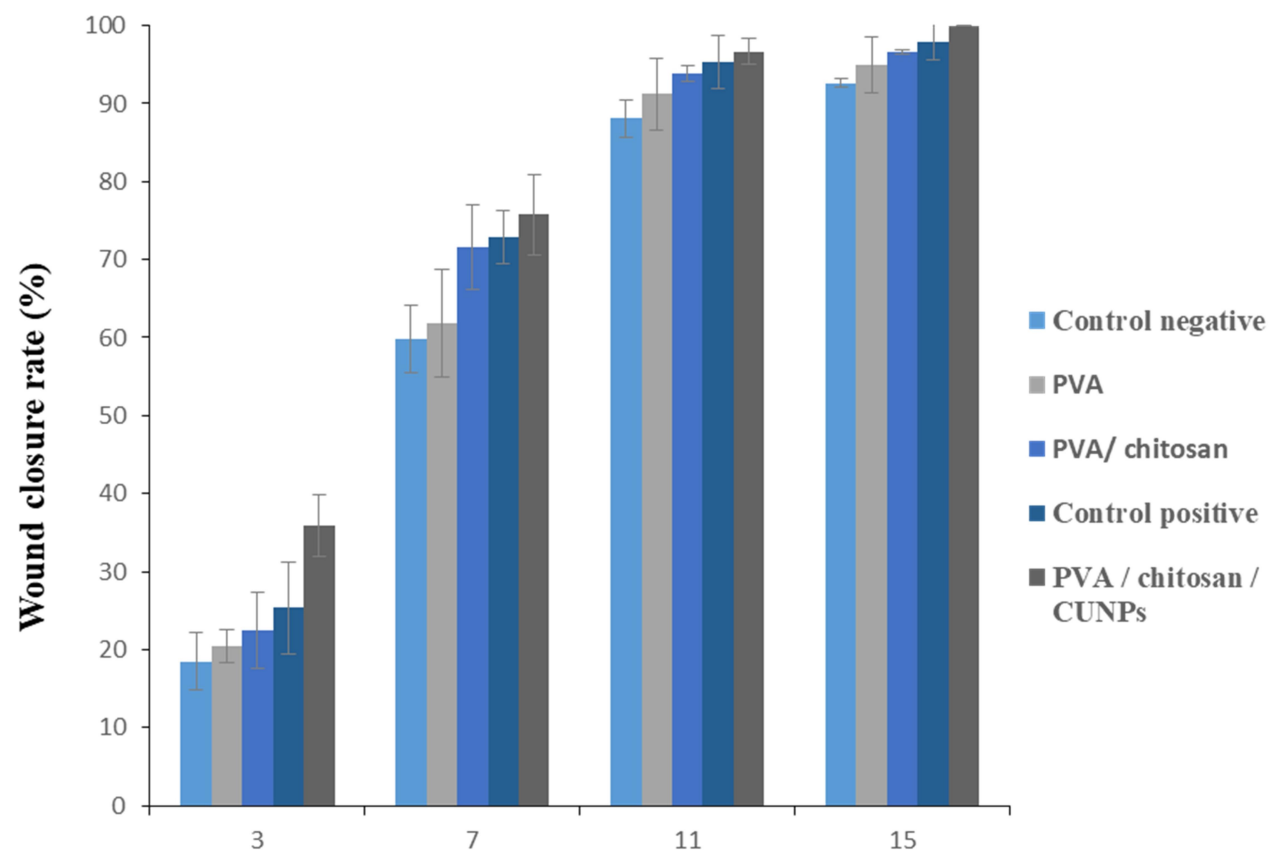

Time (Days)

Figure 10 The percentage of wound closure for the positive control, negative control, PVA, PVA/CS, and PVA/CS/CuNPs.

nanoparticles induced a sharp decrease in the wound surface area on the first day after application in mice. ${ }^{24}$

\section{Discussion}

Many scientists have shown in the literature that chitosan, PVA, PVP, and other hydrogels are good candidates in the area of wound healing and wound dressings. Furthermore, incorporation of some metallic nanoparticles such as $\mathrm{Cu}, \mathrm{Ag}$, $\mathrm{Fe}$ compounds, and $\mathrm{TiO}_{2}$ in hydrogels improves the wound healing process.

In the present work, we focused on the healing activities of electrospun nanofibers based on PVA, chitosan and $\mathrm{Cu}$ nanoparticles.

Here, the application of $\mathrm{Cu}$ ions or nanoparticles improved the antimicrobial activity of the prepared nanofibers. This is promising in the application of nanofibers as a wound dressing. The layer produced by the nanofibers is different from other textures, because with using a minimum amount of raw material, many nanofibers with high surface area were obtained. In addition, since many materials can be added to the electrospun solution in the electrospinning process, it is possible to design a variety of functional nanofibers for specific applications. Various types of inorganic NPs (such as silver, gold, copper-titanium and zinc oxide) have been shown to have potential therapeutic effects on wound healing, suppressing local skin inflammation and preventing pathogens from entering the skin. Besides, the present study showed promising antimicrobial activity, especially against Gram-positive organisms.

Wound healing is a dynamic physiological process that becomes activated after skin injury as various cells, cytokines, structural proteins and growth factors are involved in wound healing. It consists of a number of biological pathways such as hemostasis, inflammation, proliferation, and maturation. Copper directly or indirectly stimulates many factors that play important roles in the proliferation of keratinocytes and fibroblasts, epithelialization, collagen synthesis, interleukin-2 production and angiogenesis, which result in the wound being healed over a shorter time. Nanocopper has been reported to possess toxic effects on the liver and kidney, and be genotoxic and cytotoxic, along with disturbing cell membrane integrity and inducing oxidative stress, therefore combining nanocopper particles with chitosan can reduce its toxicity by decreasing the requirement for high dosages and also accelerate wound healing. ${ }^{35-37}$

\section{Conclusion}

In the present research, a new double-layer wound dressing nanofiber material with antimicrobial properties was fabricated. The external layer contained PVA/CS/CuNPs, and the lower layer included PVP. The most important benefits of nanofibers are the simulation of the natural extracellular matrix 
fiber arrangement in the body, the surface-to-volume ratio, the degree of significant porosity, and the complete interconnection of pores. In this method, a minimum amount of toxic solvents and materials were used in comparison to the method that incorporated drugs in the wound dressings. XRD, SEMEDS, and TEM showed that the incorporation of $\mathrm{Cu}$ nanoparticles was successful. The antibacterial assessment indicated that the prepared nanofibers possessed antibacterial activity against different types of microorganisms. Also in the fullthickness wound model of albino rats, the wound closure rate showed that the damaged tissue was taken care of and the wound healed in a shorter time. Making a special dressing for any type of wound, controlling the release of the drug over time and observing the process of wound healing through the dressing, are some of the suggestions that can be considered for the wound dressing industry.

\section{Acknowledgments}

The authors are grateful for the financial support from the Research Councils of Ilam University, Ilam, Iran and Northeastern University (NEU), MA, USA.

\section{Disclosure}

The authors report no potential conflicts of interest for this work.

\section{References}

1. Sen CK. Wounds and Its Burden: an Updated Compendium of Estimates. Adva Wound Care. 2019;8(2):0946. doi:10.1089/wound.2019.0946

2. Hadaegh F, Bozorgmanesh MR, Ghasemi A, Harati H, Saadat N, Azizi F. diabetes in the Islamic Republic of Iran: systematic review and meta-analysis. East Mediterr Health J. 2009;15(3):591-599. doi:10.26719/2009.15.3.591

3. Bhattarai N, Edmondson D, Veiseh O, Matsen FA, Zhang M. Electrospun chitosan-based nanofibers and their cellular compatibility. Biomaterial. 2005;26(31):6176-6184. doi:10.1016/j. biomaterials.2005.03.027

4. Kalantari K, Mostafavi E, Afifi AM, et al. Wound dressings functionalized with silver nanoparticles: promises and pitfalls. Nanoscale. 2020;12(4):2268-2291. doi:10.1039/C9NR08234D

5. Hassiba AJ, El Zowalaty ME, Webster TJ, et al. Synthesis, characterization, and antimicrobial properties of novel double layer nanocomposite electrospun fibers for wound dressing applications. Int J Nanomedicine. 2017;12:2205-2213. doi:10.2147/IJN.S123417

6. Li M, Mondrinos MJ, Gandhi MR, Ko FK, Weiss AS, Lelkes PI. Electrospun protein fibers as matrices for tissue engineering. Biomaterial. 2005;26(30):5999-6008. doi:10.1016/j.biomaterials.2005.03.030

7. Shao S, Li L, Yang G, et al. Controlled green tea polyphenols release from electrospun PCL/MWCNTs composite nanofibers. Int J Pharm. 2011;421(2):310-320. doi:10.1016/j.ijpharm.2011.09.033

8. Huang Y, Dan N, Dan W, et al. Bilayered Antimicrobial Nanofiber Membranes for Wound Dressings via in Situ Cross-Linking Polymerization and Electrospinning. Ind Eng Chem. 2018;57 (50):17048-17057. doi:10.1021/acs.iecr.8b03122
9. Hassiba AJ, El Zowalaty ME, Nasrallah GK, et al. Review of recent research on biomedical applications of electrospun polymer nanofibers for improved wound healing. Nanomedicine. 2016;11 (6):715-737. doi:10.2217/nnm.15.211

10. Kalantari K, Afifi AM, Jahangirian H, Webster TJ. Biomedical applications of chitosan electrospun nanofibers as a green polymer review. Carbohydr Polym. 2019;207:588-600. doi:10.1016/j. carbpol.2018.12.011

11. Bakhsheshi-Rad HR, Hadisi Z, Ismail AF, et al. In vitro and in vivo evaluation of chitosan-alginate/gentamicin wound dressing nanofibrous with high antibacterial performance. Polymer Test. 2020;82:106298. doi:10.1016/j.polymertesting.2019.106298

12. Bharathi BS, Stalin T. Cerium oxide and peppermint oil loaded polyethylene oxide/graphene oxide electrospun nanofibrous mats as antibacterial wound dressings. Mater Today Commun. 2019;21:100664. doi:10.1016/j.mtcomm.2019.100664

13. Zhou Y, Yang H, Liu X, Mao J, Gu S, Xu W. Electrospinning of carboxyethyl chitosan/poly(vinyl alcohol)/silk fibroin nanoparticles for wound dressings. Int J Biol Macromol. 2013;53:88-92. doi:10.1016/j.ijbiomac.2012.11.013

14. Gabriel Gabriel G, de Lima DW, de Lima F, Maria JA, de Oliveira AB, Lugao MTS. Synthesis and in Vivo Behavior of $\mathrm{PVP} / \mathrm{CMC} /$ Agar Hydrogel Membranes Impregnated with Silver Nanoparticles for Wound Healing Applications. ACS Applied Bio Materials. 2018;1(6):1842-1852. doi:10.1021/acsabm.8b00369

15. Borkow G, Zatcoff RC, Gabbay J. Reducing the risk of skin pathologies in diabetics by using copper impregnated socks.Med Hypotheses. 2009;73(6):883-886. doi:10.1016/j.mehy.2009.02.050

16. Brewer GJ. Copper in medicine. Curr Opin Chem Biol. 2003;7 (2):207-212. doi:10.1016/s1367-5931(03)00018-8

17. Palza H, Gutierrez S, Delgado K, et al. Biocide Materials Based on Polypropylene/Copper Nanoparticles. Macromol Rapid Commun. 2010;31:563-567. doi:10.1002/marc.200900791

18. Sivasubramanian KN, Henkin RI. Behavioral and dermatologic changes and low serum zinc and copper concentrations in two premature infants after parenteral alimentation. J Pediatr. 1978;93 (5):847-851. doi:10.1016/S0022-3476(78)81099-3

19. Mukherji S, Ruparelia J, Agnihotri S. Antimicrobial Activity of Silver and Copper Nanoparticles: variation in Sensitivity Across Various Strains of Bacteria and Fungi. In: Cioffi N, Rai M, editors. Nano Antimicrobials. Berlin, Heidelberg: Springer; 2012.

20. Haron MJ, Jahangirian $\mathrm{H}$, Shah Ismail MH, et al. Antifungal properties of phenyl fatty hydroxamic acids and their copper complexes synthesized based on canola and palm kernel oils. Asian J Chem. 2013;25(8):4183-4188. doi:10.14233/ajchem.2013.13883

21. Jahangirian H, M J H, M H S, Abdollahi Y, Rezayi M, Vafaei N. Well diffusion method for evaluation of antibacterial activity of copper phenyl fatty hydroxamate synthesized from canola and palm kernel oils. Dig J Nanomater Bios. 2013;8(3):1263-1270.

22. Ashfaq M, Khan S, Verma N. Synthesis of PVA-CAP-based biomaterial in situ dispersed with $\mathrm{Cu}$ nanoparticles and carbon micro-nanofibers for antibiotic drug delivery applications. Biochem Eng J. 2014;90:79-89. doi:10.1016/j.bej.2014.05.016

23. Perelshtein I, Applerot G, Perkas N, et al. CuO-cotton nanocomposite: formation, morphology, and antibacterial activity. Surf Coat Tech. 2009;204(1-2):54-57. doi:10.1016/j.surfcoat. 2009.06.028

24. Archana D, Singh BK, Dutta J, Dutta PK. In vivo evaluation of chitosan-PVP-titanium dioxide nanocomposite as wound dressing material. Carbohydr Polym. 2013;95(1):530-539. doi:10.1016/j. carbpol.2013.03.034

25. Mishra SK, Mary DS, Kannan S. Copper incorporated microporous chitosan-polyethylene glycol hydrogels loaded with naproxen for effective drug release and anti-infection wound dressing. Int J Biol Macromol. 2017;95(1):928-937. doi:10.1016/j.ijbiomac.2016.10.080 
26. Thakar M, Jagani HV, Narayanan K, Tiwari M, Rao JV. Biosynthesis and wound healing activity of copper nanoparticles. IET Nanobiotechnology. 2014;8(4):230-237. doi:10.1049/iet-nbt.2013.0052

27. Wahid F, Wang H-S, Lu Y-S, Zhong C, Chu L-Q. Preparation, characterization and antibacterial applications of carboxymethyl chitosan/CuO nanocomposite hydrogels. Int $J$ Biol Macromol. 2017;101:690-695. doi:10.1016/j.ijbiomac.2017.03.132

28. Fu J, Qiao J, Lv H, Ma J, Yuan X-Z, Wang H. Alkali Doped Poly (vinyl alcohol) (PVA) for Anion-exchange Membrane Fuel Cells: ionic Conductivity, Chemical Stability and FT-IR Characterizations. ECS Trans. 2019;25(13):15-23. doi:10.1149/1.3315169

29. Yang JM, Su WY, Yang MC. Evaluation of chitosan/PVA blended hydrogel membranes. J Membrane Sci. 2004;236(1-2):39-51. doi:10.1016/j.memsci.2004.02.005

30. Paipitak K, Pornpra T, Mongkontalang P, Techitdheer W, Pecharapa W. Characterization of PVA-Chitosan Nanofibers Prepared by Electrospinning. Procedia Eng. 2011;8:101-105. doi:10.1016/j.proeng.2011.03.019

31. Sumi K, Tsuchiya Y. Thermal decomposition products of poly(vinyl alcohol). $J$ Polymer Sci. 1969;3151-3158. doi:10.1002/ pol.1969.150071111

32. Murugan S. Investigation of the synergistic antibacterial action of copper nanoparticles on certain antibiotics against human pathogens. Int J Pharm Pharm Sci. 2018;10(10):83-86. doi:10.22159/ ijpps.2018v10i10.28069
33. Slavin YN, Asnis J, Häfeli UO, Bach H. Metal nanoparticles: understanding the mechanisms behind antibacterial activity. J Nanobiotechnology. 2017;15(1):65. doi:10.1186/s12951-017-0308-z

34. Manzl C, Enrich J, Ebner H, Dallinger R, Krumschnabel G. Copperinduced formation of reactive oxygen species causes cell death and disruption of calcium homeostasis in trout hepatocytes. Toxicology. 2004;196(1-2):57-64. doi:10.1016/j.tox.2003.11.001

35. Kristan LS, A A W, Dodd AW, et al. Chitosan coating of copper nanoparticles reduces in vitro toxicity and increases inflammation in the lung. Nanotechnology. 2013;24(39). doi:10.1088/0957-4484/24/ $39 / 395101$

36. Rakhmetova AA, Alekseeva TP, Bogoslovskaya OA, et al. Woundhealing properties of copper nanoparticles as a function of physicochemical parameters. Nanotech Russia. 2010;5(3-4):271-276. doi:10.1134/S199507801003016X

37. Gopal A, Kant V, Gopalakrishnan A, Tandan SK, Kumar D. Chitosan-based copper nanocomposite accelerates healing in excision wound model in rats. Eur J Pharmacol. 2014;731:8-19. doi:10.1016/ j.ejphar.2014.02.033
International Journal of Nanomedicine

\section{Publish your work in this journal}

The International Journal of Nanomedicine is an international, peerreviewed journal focusing on the application of nanotechnology in diagnostics, therapeutics, and drug delivery systems throughout the biomedical field. This journal is indexed on PubMed Central, MedLine, CAS, SciSearch ${ }^{\circledR}$, Current Contents ${ }^{\circledR} /$ Clinical Medicine,

\section{Dovepress}

Journal Citation Reports/Science Edition, EMBase, Scopus and the Elsevier Bibliographic databases. The manuscript management system is completely online and includes a very quick and fair peer-review system, which is all easy to use. Visit http://www.dovepress.com/ testimonials.php to read real quotes from published authors. 